\title{
MARK ROTHKO: \\ A Cross-Modal Approach
}

ANN SARNO

SYNESTHESIA IS NOT ONLY HIGHLY INSTRUMENTALBUT PRIMARY IN OUR FIGURATIVE THOUGHT AND EXPRESSION. THE OVERLAPPING OF SENSORY MODALITIES CAN BE USED TO ELUCIDATE COMPLEX LAYERS OF PERCEPTION THROUGH A UNIVERSAL TYPE OF METAPHOR. IN REGARDS TO ABSTRACT EXPRESSIONISM, A VISUAL STRAGEDY THAT IS VAGUE AND VAST, REFERRING TO ALTERNATIVE MODES OF PERCEPTION TO COMPREHEND PAINTING PROVES EXTREMELY USEFUL WHEN EXERCISED WITH DISCRETION. THE RESEARCH I HAVE CONDUCTED INCLUDES PSYCHOLOGICALEXPERIMENTS, STUDIES ON COLOR, GRAVITY, PHYSICS, ACOUSTICS, ARCHITECTURE AND ART CRITICISM. BY ANALYZING GRAVITY, VOLUME, PITCH WEIGHT ANDSATURATIONIN MUSIC, I HAVE IDENTIFIED THEM IN ABSTRACT EXPRESSIONIST MARK ROTHKO'S ART. ALTHOUGH THESE COMPONENTS ARE MUTABLE IN ROTHKO'S CAREER, THEY ARE CONSISTENTLY PRESENT. 


\section{"I became a painter because I wanted to raise painting to the level of poignancy of music and poetry."}

\section{INTRODUCTION}

Mark Rothko once proclaimed "I became a painter because I wanted to raise painting to the level of poignancy of music and poetry." This tragedy which Rothko hoped to communicate through visual art is often experienced while listening to music. Even before Rothko's time, painter Wassily Kandinsky yearned to replicate the emotional impact of music in his art. Indeed, the visual and audible arts have been related since the time of Aristotle, who asserted in De Sensu, "we may regard all colours as analogous to the sounds that enter into music." The competitive relationship between music and art has an intricate history which is currently under review by neuroscientists.

\section{SYNESTHESIA}

Evidently, music, particularly Mozart's Don Giovanni, greatly influenced Rothko throughout his career. As a college student who lived in Rothko's flat for a short interim recalled "in the evenings he would lie on the couch for hours saying nothing, just contemplating or looking at one of his pictures that was hanging up and listening to music." In order to evoke the same energy and emotions as the opera, Rothko painted in a studio saturated with music. As a self-taught mandolin player and pianist, he used musical expression to arrive at emotional realization in the past. Additionally, Rothko's musical talent resulted in his marriage to his first wife. While strolling through Central Park, Edith was attracted to Rothko's beautiful, enrapturing mandolin playing. Although he ultimately abandoned music for painting, it is clear that it impacted his life as well as his cognitive processes.

Untitled 1932 is a blatant attempt to convey his passion for music. The ethereal string quartet plays vigorously. Rich blues and browns project a solemn and nearly spiritual quality. Because he had tremendous respect for musicians, especially the classics, Rothko "could spend very happy hours, flat on his back on the couch, listening to Mozart."iii Music served as a muse and an aphrodisiac for him.

Neuroscientists have considered the synthesis of various modes of perception in the brain for decades. They have coined the term, "synesthesia," most simply defined as "inter-sensory association." While several forms of synesthesia exist, the most dominant type melds the domains of the seeing and hearing. Additionally, overlaps between the bodily kinesthetic and music have also been noted. Resulting from a severe psychological disorder, color appears spontaneously to synesthetes upon perceiving auditory stimuli.

Kandinsky may have asserted himself as a synesthete, but he probably was not. This self-declaration was more likely an egotistical attempt to propagate his unique and advanced painting abilities. On the other hand, David Hockney and his neurologist Richard Cytowic maintain that Kandinsky possesses this extremely rare condition.iv He painted sets for Stravinsky's opera Rossignol by listening to the music in his studio and using the color and rhythm he perceived from the music. Whether or not these artists truly suffered from severe synesthesia is questionable. Their claims however, support the notion of translating music into color and the audio/ visual cross modal perception of paintings.

Scientists have broadened their definition in light of the nonsynesthete's capacity to transfer between sensory realms through learned metaphor. According to Bulat M. 


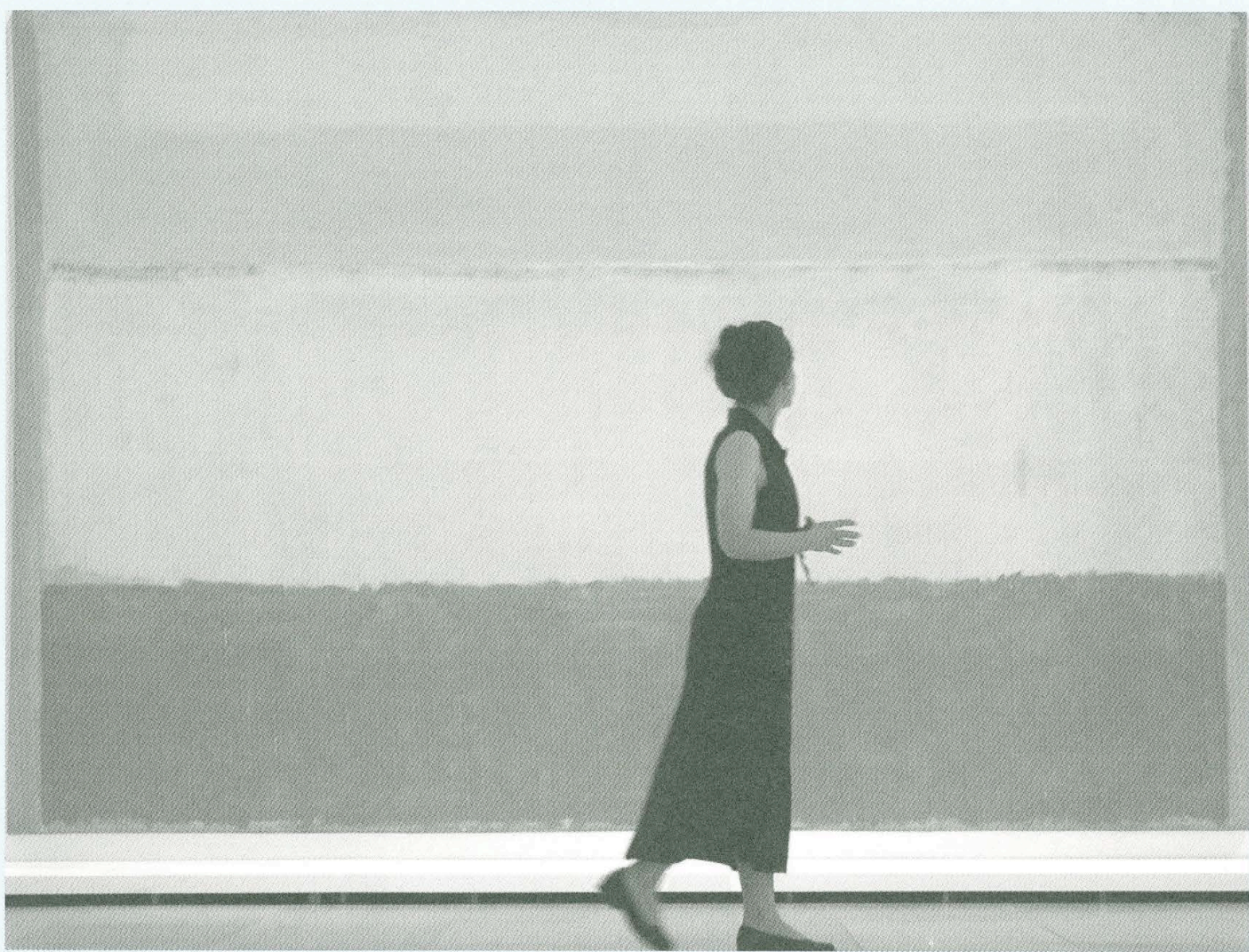

Galeyev, scientist and artist, "synesthesia is an essential aspect of language and, more generally, of all figurative thinking, including all imaginative thinking (for all kinds of art, including music)." Synesthesia is not only highly instrumental, but primary in our figurative thought and expression.

I do not propose that Rothko was a synesthete. Nor do I propose that the abstract elements of painting - line, color and form-are synonymous with the line, pitch and timbre of music. Creating cross-field analogies is arbitrary if not futile. Neurobiologist Jean-Pierre Ternaux maintains, "Transferring structural or numerical features from one domain to another may thus in many cases result in some quite bad category mistakes, i.e. mistaking principles of organization in one domain as valid for other, totally different domains." ${ }^{\prime}$ The overlapping of modalities can be used instead to elucidate complex layers of perception through a universal type of metaphor. In regards to abstract expressionism, a movement that is vague and vast, referring to alternative modes of perception to comprehend painting proves extremely useful when exercised with discretion.

The research I have conducted includes psychological experiments, studies on color, gravity, physics, acoustics, architecture and art criticism. Although my sources seem far and too many in between, I have discovered several remarkable elements present in Rothko's work which reify the con- 
cept of synesthesia. By analyzing gravity, volume, pitch, weight and saturation in music, I have recognized them in visual art. These components are mutable in Rothko's career but consistently present. "The Subway Series," "Multiforms", "Fat Rectangles" and "The Houston Chapel" distinctly engage the spectator with cross-modal effects. This presentation highlights the synesthetic qualities of his paintings from each period.

\section{GRAVITY}

Beginning with the Subway Series, Rothko facilitates gravitational tension through hyperbolized body proportions. In "Subway of the I930s," the height of the figures strains from the platform to the ceiling. With the exception of the young woman depicted on the left, the images have a striking resemblance to caryatid or atlantes figures. The caryatids of the Porch of the Maidens at the Erectheum extend gracefully from the entablature. Although they are very serene and stoic, with their hands positioned calmly at their sides, the immense weight they support with their heads is alarming. These women serve as architectural constructs, as emblematic retribution for the females of the village Caryae who betrayed the Greeks by siding with the Persians

The expressionless faces of the Subway figures evoke the same quiet stillness as the maidens. Like the Greek sculptures, they do not appear punished by their physical state, but their body language indicates tension. Although they do not uphold the architecture of the station and the woman on the right leans against a column to support her own weight, it appears that the subterranean environment would collapse in their absence.

Scientist Bulat M. Galeyev has examined the properties of gravity in visual art. He proposes that there are two distinct versions of gravitational synestheses: "spatial or static" and "kinesthetic". The static applies to abstract art, "Spatial synestheses arise due to our experience of the static gravitational field and arise in static arts (such as painting, architecture, etc.). For example, the horizontal line at the lower edge of a picture is perceived as more 'heavy' and 'stable' than the vertical lines that delineate the sides."vii The contrast between this sense static gravitational synesthesia portrays the thick, horizontal ceiling and floor and the vertical floppy, emaciated subway figures. Because the precarious stability of caryatids and of Rothko figures is assimilated into our own perceptions of gravity, the onlooker cannot evade the sense of weight expressed in these works. This kinesthetic synthesis is also applicable to later work, particularly his signature horizontal compositions.

In contrast contextually, the caryatids are not responsible for upholding their surroundings nor held blatantly against their will. Rothko's figures and the caryatids share states of immobility that are exacerbated by looming gravity, whether it is the heaviness of an entablature or a boisterous New York City street. Similar to the caryatids, the individuals in the subway station cannot control or predict their own mobility. The arrival and departure of the trains are beyond their locus of power. Their "sentence" of waiting is indefinite. They cannot predict the duration of their time in the station or influence the speed and regularity of public transportation.

Clearly, they possess the freedom to leave at anytime to pursue other means of transport but this is unlikely. Once an individual engages in the act of waiting, passed time resembles progress towards the goal. Presumably, the longer one has waited, the less time they have to wait in the future. The omnipresent gravity in this setting, due to the psychological captivity and the physical confinement, agitates this psychological trap, and anxiety ensues.

Rothko's rejection of the figure in later works expands the perception of this spatial synthesis to the spectator's realm. Through the depiction of physical bodies, viewers become witnesses. Without figurative representation, onlookers do not merely observe but experience. The Subway figures are surrogate victims of gravity, whereas Rothko's untitled work elicits the viewer's own kinesthetic response.

Gravity is also a component of sound, which is increasingly 
relevant in Rothko's Multiforms: “...gravitational-audile and gravitational-visual synestheses rise to the level of consciousness. They can be found in ordinary speech in the form of veiled metaphors and conventional allegories based on intersensory transfers, such as baritone' (heavy sound) 'light music' 'heavy chords' etc." viii The properties of gravity correlate with the protopathic element of sensations and are exposed in the most typical emotional responses such as a "heavy mood" being weighed down or as light as a feather.

Number 18 for example, includes many fluffy, light bodies that do not appear burdened with gravity. Rothko's loose application of paint and the undaunted organization of forms suggest buoyancy. They are not restricted like the subway figures but have a nimble autonomy. Their weightless quality compares with the lightness of musicians like Scriabin, Shoenberg and Messiaen. Without concrete borders, the forms appear to float and swirl in motion like the nonchalance of Shoenberg's compositions.

\section{SOUND AND COLOR SATURATION}

Visual movement and actions are clearly linked with the creation of sound. Consequently, listeners will often create an internal image which depicts the creation of a sound. Marching or beating a drum may come to mind when an individual hears a certain sound and assumes its origins. Neurobiologist Jean-Pierre Ternaux distinguishes two groups of sound-producing actions, ballistic and sustained. Ballistic refers to "a brief, concentrated effort immediately followed by a phase of relaxation, as in the case of hitting or kicking and in performance on percussion instruments and certain keyboard instruments such as the piano ... the moment of impact is immediately followed by a shorter or longer period of energy dissipation in which the sound usually has a decaying shape." ix This vibrating description of shock followed by decay is reminiscent of these early multiforms.

The blue form in the upper register for example, has a thick, concentrated application of paint that diffuses and decomposes. Like striking a chord on the piano, the sound is initially sharp and rich and then it becomes softer and dispersed. This is also true of the blue forms in Untitled 1947. Whether communicated by a stroke of a paintbrush or piano keys, the reverberating effect is the same. The spectator perceives the initial, intense effort and the subsequent ease of the ballistic. Vibrating energy is conveyed in lieu of intersensory transfers.

\section{"Saturation [of color] is comparable to volume [of sound] in many respects.}

In the early I950's, Rothko's style took a dramatic turn. The majority of his signature compositions were created during this phase. Although they are renowned for their bold color, it is not their most significant feature. In fact, color is not the driving force of the emotion in this work. Saturation, rather than the distinct color, engenders more visual force. D'Andrade and Egan (I974) discovered that "color-emotion associations were not due predominately to hue (i.e. the spectral wavelength) but to the degree of saturation and brightness of the color." $\times$ Rothko, who always insisted his work was not about color, would probably prefer this approach.

Saturation is comparable to the volume in many respects. The amount of paint or the amount of sound is more aggressive in greater magnitudes. If volume fades, or color fades, the effect is more gentle or weaker. In Number 7 of I951, Rothko presents a variety of color tones and levels of saturation. The top register of blue rubbed cryptically over orange is an example of low saturation. The under painting is highly visible beneath the soft blue. Each tier becomes progressively more saturated. Thick, light green spreads 


\section{"Rothko's compositions do not rely on color tone alone to communicate. Saturation and volume are essential to the emotional force of his work."}

nearly to the edges completely concealing the orange. A narrow band of white is another example of low saturation whereas the final tier is punctuated by a heavy, dense red. These fluctuations of saturation are similar to fluctuations in volume. The wispy blue is meek, translucent, barely visible and barely audible. It attempts to conceal the orange but is too weak. Green booms with greater intensity and overtakes the orange under layer. The center of this form is slightly yellowed and softer but still opaque. The ending red is most aggressive because of its high saturation. Unlike the other registers, there is no indication of color change or brushstrokes. It is loudest of all. These forms compete to be seen as music played at a variety of volumes compete to be heard. Strength or weakness is communicated by magnitude. In light of the perceivable discrepancies in volume or saturation, it is clear which forms dominate in this composition.

An even stronger illustration of this idea is a comparison of three works with nearly identical color palates but very distinct levels of saturation. Untitled 1955, Yellow and Gold 1956 and Untitled 1956 are composed of yellows and oranges. Despite the similarities in hue, the level of saturation in each painting engenders a very different effect. Untitled 1955 has a very translucent, blurred application of paint. It lacks volume and visual strength; consequently, it is very soothing to the eye. The opacity in Yellow and Gold 1956 are relatively opaque but not nearly as saturated as Untitled 1956. The yellows in both compositions are nearly the same but have a completely different result. Inarguably, the untitled piece is extremely forceful if not violent due to the magnitude of saturation. It is clear to the onlooker that the final canvas is piercing in volume in relation to the gentle volume of Untitled 1955. Rothko's compo- sitions do not rely on color tone alone to communicate. Saturation and volume are essential to the emotional force of his work.

\section{LIGHTNESS AND PITCH}

The next comparison of Untitled 1954 and Purple Brown, 1957 demonstrate the correlations between visual lightness and auditory pitch. Experiments have demonstrated that people make consistent associations between particular pitches and value. As early as the I940's, researchers recognized that "Auditory stimuli that are lower in frequency typically evoke visual sensations of stimuli that are darker, and auditory stimuli that are higher in frequency typically evoke visual sensations of stimuli that are lighter." xi The light visual stimuli presented in Untitled 1954 and the dark visual stimuli presented Purple Brown generate distinct cross-modal associations. As the spectator attempts to derive meaning from these works, the element of pitch is highly conductive to his or her perception of the painting.

In a recent study in the American Journal of Psychology, subjects were asked to assign auditory pitches to a visual scale of value on a luminescent column. Researchers concluded "A clear relationship was seen between the direction and size of an auditory melodic interval and the visual luminosity judged as fitting best with that interval. Lighter visual stimuli were judged to fit best with descending intervals. Additionally, the size of melodic intervals (within the octave range used) led to preferences for more extreme levels of lightness or darkness; specifically, visually lighter stimuli were preferred for larger ascending intervals than for smaller ascending intervals, and visually darker stimuli were preferred for larger descending intervals than for smaller descending intervals."xii In summary, scientists 
have proved a precise relationship between pitch and visual lightness. This interplay of the senses produces the emotive characteristics of Rothko's work.

Like the previously discussed component of saturation and volume, perceived pitch contributes to the amount of perceived energy in the composition. For example, Untitled 1954 would be categorized as visually bright, especially in direct contrast to Purple Brown whose darker palette of brown, purple and black would pertain to a very dim level on the luminescent scale. The viewer is likely to associate brightness and high pitch with an increased level of energy. Accordingly, low pitch and low visual light would be related to a decreased level of energy.

This energy relates to the previous discussion of gravity and weight of the Multiforms and Subway Series. Referring to Black on Dark Sienna on Purple, I960, the wide rectangles hover clumsily as though they are unsure where to settle. In an anxious state of hesitation, they express a sluggish kinetic pattern of behavior which induces a lethargic, yet tense mood. The slow, cumbersome compositions in his later years reflect his own heavy, somber mood. Rothko translates his bouts of depression onto many of his canvases. In turn, the hulking forms impose their immensity on the viewer.

\section{ENEGRY AND EMOTION}

Researchers have also noted this connection between energy or movement and emotion. Speed, Franc and Graves say, is "a rapid movement (allegro) is generally more joyous than a slow movement. A person who is depressed has lower muscular tone, so to speak, compatible with slow body movements. Consequently, a slow form in music, associated, thanks to another explicative link, with a certain type of movement (a kinetic pattern of behavior) can evoke an emotional state."xiii Ironically, Rothko's work, in addition to his own physical condition, adheres to this pattern. Black on Dark Sienna on Purple reflects this lack of physical exuberance. Without marked brightness or pitch, nor intense saturation or volume, the forms appear weak, tired and muted.

This description cannot be separated from Rothko's own body. A relative vividly recalled that "he had a body like a ferryboat tied to a port."xiv This image recalls a thick clumsy shape banging against a rectangular frame, an image of a frustrated body that lacks direction and autonomy. This insecure and confined positioning recalls the organization of the Subway Series. Just as these rectangles may be imagined as trapped or as emerging, the individuals in the subway station are capable of waiting or leaving. It is this hesitation, the uncertainty of one's due course that can be gleaned from considering the kinesthetic cross perceptions of visual art.

Art Historian Anna Chave also recognizes the kinesthetic properties of Rothko's paintings. Regarding to composition Chave observes, "His rectangles did not simply define the picture plane: they may be seen as floating parallel to that surface, but they are also perceived as locked into spatial struggles both against the picture plane and against each other, as variously obtruding from and receding into space, and in some viewer's eyes as evoking mysterious and unsounded depths" xv Despite Rothko's obvious avoidance of any reference to the third dimension, it is nearly impossible to perceive these works without reverting to spatial metaphors.

This perplexing organization disturbs the spectator. Determining the nature of the black, the dark sienna, and the purple is a daunting task. However, Rothko's title, useful to a degree, informs us that the black is on the dark sienna which is on purple. This would lead one to conclude that the black is above the dark sienna but the dark sienna is above the purple. A confusing juxtaposition places black as the dominant, emerging form which violates the viewer's expectations, for darker colors are supposed to recede in most paintings. As the audience struggles they ultimately rely on cross-modal processes to perceive these images. 
Again, Rothko plays with the viewer's sense of gravity. Is the purple dissolving or receding? How does the dark sienna act to separate these forms? Chave asserts that "By leaving separations among the rectangles, or between them and the edge of the support, and by layering and modulating the surfaces of the rectangles, Rothko created a subtle visual gyration or friction, as between entities that are close to touching but stop just short or layers that closely blanket one another while retaining pockets of space between them"xvi This spatial organization befuddles the observer. Chave continues that "A subtle but tense visual tug-of -war is waged in Rothko's canvases between the later pull of the individual rectangular areas and the vertical movement of the gestalt comprised by the stack of rectangles." xvii This perpetual "tug-of-war" could only be recognized through cross-modal association.

\section{"Tragically, Rothko would never see the realization of his most dramatic work."}

The function of the borders is particularly instrumental towards comprehending the position of these forms. Here, Chave discerns that, "By contrast with the insubstantiality of the borders in Rotko's paintings, the rectangles take on the appearance of something material or in the process of materializing and emerging. "xix It would follow then that the black form emerges before the dark sienna whereas the purple materializes behind the dark sienna border.

\section{THE HOUSTON CHAPEL}

Tragically, Rothko would never see the realization of his most dramatic work. The Houston Chapel was not completed until after his suicide in I970. He ultimately achieved his desire to convey tragedy and poignancy in this project. Although the canvases are completely devoid of contrast and consist of a limited palette of mixed blacks and reds, they are profound and engaging. While the dearth of imagery stifles stimulation, the cross-modal synetheses generate the acute drama Rothko aspired to inflect on his audience.

In response to the stark canvases, art historian Robert Rosenblum commented, "It as if the entire current of Western religious art were finally devoid of its narrative complexities and corporeal imagery, leaving us with the dark, compelling presences that pose an ultimate choice between everything and nothing ... the very lack of overt religious content here may make Rothko's surrogate icons and altarpieces, experienced in a nondenominational chapel, all the more potent in their evocation of the transcendental." $x$ ix By creating a bare environment, the large scale canvases immerse the spectator. Content and scale do not act as barriers between the viewer and the work. Rather, if "you paint the larger picture, you are in it..." $x x$ In this regard, Rothko hoped to incorporate the onlooker's kinesthetic perception.

The Houston Chapel inspired composer Morton Feldman; The Menil Foundation recruited him in I97I to write a musical composition in Rothko's memory, entitled The Rothko Chapel. With The Houston Chapel as his inspiration, Rothko's canvases were Feldman's direct source. The musical program states "I tried to create a music that walks the thin line between the abstraction of all art and the emotional longing that characterizes what it is to be 'human'. The chorus symbolizes art's abstractness; the sola viola, the need for human expression. It is only at the end of the work that I think of Rothko and his own love for melody. Here, I collage a Hebrewesque melody which I wrote thirty years ago-at sixteen."xxi Clearly, Feldman noticed the audible nature of Rothko's work.

Although I have not listened to this particular song, I am doubtful that Feldman could truly captivate the essence of the Chapel with a violin and chorus. Feldman's ambition, however, demonstrates Rothko's appeal to audio perception. These bare canvases with little evidence of brushwork and no contrast evoke a simpler and purer sound. 
Recalling the previous discussion of ballistic sound producing actions, Rolf Ingre Godoy designated the term sustained sound-producing actions for its opposite. Ballistic actions have a definite beginning and end. Sustained sound producing actions implicate "the more continuous effort required in blowing, singing and bowing, and the shape of the sound may just as well be flat or even ascending (ie having a crescendo) because of the continuous transfer of energy in the sound-producing actions."xxii Sustained sound producing actions have no visible start or stop. Whereas the ballistic is finite, the sustained is infinite. The Houston Chapel exudes the notion of infinity. Individually, canvases reverberate without any discernable fluctuation of color or texture so each distinct painting lacks indication of variation.

Without discrete interruption of color and tone, the panels in the Chapel exude a constant, guttural tone. Considering the cross-modal association with pitch, it is likely that the spectator would correlate these works with a low pitch. With respect to the sustained nature of these canvases, this pitch is monotone, or "continuance or uninterrupted repetition of the same tone; the utterance, in speech or singing of a number of successive syllables without change of pitch."xxiii Monotone has been used in certain musical scores and even as a special effect in opera. In Act Two in the finale of Mozart's Cosi fan tutte, for example, the notary speaks in monotone to enhance the drama of the scene. His flat and even tone is awkward and discomforting. Monotone also appeals to the ethereal environment in the Chapel through prayer and chanting.

Monotone exudes a disquieting constancy. The sustained, consistent volume exhibited by the Houston Chapel crosses through the spectators' audio, visual and kinesthetic modalities. Fixed tone is extremely disconcerting to auditory perception, so listening to a sustained tone for a period of time agitates an individual. The lack of contrast or variety is in direct opposition with the dynamic pitches in the natural world. Without interrupting the same tone over time, a state of anxiousness and pressure is induced. A monotone alarm is a blatant example of this auditory stress. The alarm is monotone because the sustained pitch is so uncomfortable. We respond immediately to the noise.

The effect of the Houston Chapel canvases are marked by this phenomenon. A beholder will search futilely for evidence of contrast or change in the panels. With the exception of a few subtle color changes, the viewer will be unable to see beyond the uniform velvety surface of the canvases. Just as a person listening to a monotone prayer or song, he or she innately longs for relief from the same sustained pitch. It is something that is impossible to perceive in the Chapel. Consequently, a state of hopelessness overwhelms the spectator. The effect of monotone is violent and engrossing. Whether it is experienced through the ears or eyes is immaterial, the subject is helpless and tortured by the steady, immutable tone. The emotional poignancy here that Rothko determined to instill in his audience is indisputable.

\section{CONCLUSION}

After assessing the elements of gravity, volume, pitch and tone in the domain of visual art, it is evident that it is conductive to understanding particular aspects of abstract expressionist works. There is a fundamental relationship between all realms of perception that cannot be overlooked during our interpretive processing. Although most individuals will never experience a crossing of modalities as severe as a diagnosed synesthete, it is inevitable that we rely on multiple forms of perception to comprehend visual stimuli. Trepidation to cross these domains of sensory modalities and reluctance to place music and art on the same level exists among many stubborn artists, critics and musicians. In response to the Armory Show in Chicago in I9I4, I believe Henry McBride says it best, "What was the use kicking because painting had become another form of music?"xxiv Or has music become another form of painting? From the synesthetic perspective, there is no question. The finest music has lightness, saturation and weight. The finest art has pitch, volume and tone. Both realms rever- 
berate with the capacity for emotional projection. Mark Rothko's fascinating career substantiates the credibility of the cross-modal approach.

\section{ENDNOTES}

i. Breslin, I73.

ii. Breslin, 173 .

iii. Breslin, 174 .

iv. "David Hockney's melodic palette," 70-2

v. Galyev, $120-34$

vi. Godoy, $326-28$

vii. Galyev, 120-34.

viii. Galyev, 120-34

ix. Godoy, 32 6-28

x. Hupka, $156-78$.

xi. Karwoski, Osgood, I942, Marks, 1975, 1978; Orman, I933, as cited in Hubbard

xii. Hubbard

xiii. Ternaux, 321-22

xiv. Breslin

xv. Chave, 128 .

xvi. Chave, II'

xvii. Chave, $132-33$.

xviii. Chave, I84.

xix. Ashton, 184-85.

$\mathrm{xx}$. Ashton, 122.

xxi.Ashton, 185 .

xxii. Godoy, 326-28

xxiii. Webster Dictionary

xiv. Risatti

\section{REFERENCES}

Aristotle. De Sensu et Sensibilibus. Trans. Art Ross. New York Arno Press, 1973.

Ashton, Dore. About Rothko. New York: Oxford University Press, I983.

Breslin, James E.B. Mark Rothko, Chicago: University of Chicago Press, 1993.

Chave, Anna. Mark Rothlo: Subjects in Abstraction. New Haven: Yale University Press, cig89.

"David Hockney's melodic palette". U.S. News and World Report. I07:I9 (November 13, I989) 70-2

Glimcher, Marc. Ed. The Art of Mark Rothko; Into an Unknown World. New York: Clarkson N. Potter, inc., r99r.
Hubbard, Timothy L. "Synesthesia-like mappings of lightness, pitch and melodic interval. American Journal of Psychology. I09:2 (Summer I996) 219-39.

Hupka, Ralph B. et al. "The colors of anger, envy fear and jealousy: a cross-cultural study." Journal of Cross-Cultural Psychology. 28,2 (March 1997) 156-178)

Galyev, Bulat M. International society for the Arts, Sciences and Technology. "Evolution of Gravitational Synesthesia in Music: to Color and Light!" Leonardo. 36:2 (2003) 129-34.

Godoy, Rolf Ingre. International society for the Arts, Sciences and Technology. "Motor-Mimetic Music Cognition" Leonardo. $36: 4(2003) 326-328$.

International society for the Arts, Sciences and Technology. "Intersenses and new Technologies." Leonardo. 36:4 (2003) 316326.

Jungheinrich, Hans-Klaus. Trans. Sherbert, Catherine.

"Lachrymae" Munich: ECM Records, 1993.

Poast, Micheal. "Color Music: Visual Color Notation for Musical Expression." Leonardo.33:3 (2000) I-5.

Risatti, Howard. "Music and the Development of Abstraction in America: The Decade Surrounding the Armory Show." Art Journal. 39:I. (Fall r979)

Serota, Nicholas. Ed. Mark Rothko. London: Tate Gallery Publishing Limited, 1987.

Ternaux, Jean-Pierre. International society for the Arts, Sciences and Technology. "Synesthesia: A Multimodal Combination of Senses. Leonardo, 36:4 (2003) 32I-2.

Wood, Tony. "Prisoners of Paradise: The caryatids and atlantes of St. Petersburg." Things Magazine. 17:I8 (Autnumn 2003) II4. 